\title{
The influence of the applied window function and sampling frequency on the assessment accuracy of the turbine engine in flight control condition based on its ground tests
}

\author{
Karol Golak ${ }^{1, *}$, Pawet Lindstedt ${ }^{2}$ \\ ${ }^{1}$ Faculty of Mechanical Engineering, Bialystok University of Technology, Wiejska 45C street, 15-351 \\ Białystok, Poland \\ ${ }^{2}$ Air Force Institute of Technology, Księcia Bolesława 6 street, 01-494 Warszawa, Poland
}

\begin{abstract}
The article presents the basis of the method allowing to assess the state of control condition of a turbine jet engine during the plane flight when the input signal to the engine is unpredictable interference signal ,, $z$ ". Method is based only on signals acquired during engine ground test when the input signal is ", $w$ " delivered by technical support using the engine control lever (DSS). The control state of the engine both from the set value ", $w$ " and , $z$ " is expressed by the quotient of its cross power spectral densities (in frequency domain). The way of transition from the frequency domain to the time domain was presented, it allows to obtain step responses of engine from ,, $z$, and ,w”, greatly facilitating the interpretation of the obtained results.. The analysis of the influence of choosing types of the window function and signals sampling frequency on the accuracy of the proposed model has been carried out.
\end{abstract}

\section{Introduction}

The aviation engine is used during the flight when, apart from the ,w” signal set by pilot using the engine control lever (DSS), it is also affected by unpredictable interference signal , $z$ " delivered from the environment. Engine is adjusted on the basis of signals recorded during its ground tests, when the input signal is only the signal ,w" from the DSS, and the signal ,, $z$ " has low power and are constant so it is often overlooked. This may lead to a situation where the aircraft properly adjusted during ground tests from the , $w$ " signal may react inappropriately to the ,, $z$ " interference signals occurring during the flight. It may lead to an undesirable change in the rotational speed (so-called vibrations and fluctuations of rotation), and even its stalling. It is also known that improving the quality of the engine from , $w$ " (on the ground) causes deterioration of the quality of the engine from ,, $z$ " (in flight) $[1,2,3,5,8]$.

\section{Theoretical basis}

The simplified diagram of the aircraft jet engine rotational speed automatic control system jet engine can be reduced to a standard scheme of the automatic control system (Fig. 1.). To derive a model describing the assessment of the control quality of a jet engine with input ,, $z$ " (during a flight) using only signals measured with input ,, $w$ " during its standard ground tests, it is necessary to identify the transfer functions of individual elements of the automatic control system.

\footnotetext{
${ }^{*}$ Corresponding author: k.golak@pb.edu.pl
} 


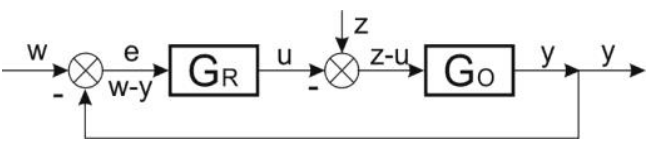

Fig. 1. Simplified diagram of the jet engine rotational speed control system, where: $G_{R}$ - controller transfer function, $G_{O}$ - object transfer function, $w$ - input signal (setpoint using the engine control lever), $z$ - input signal (interference), $y$ - output signal (rotational speed), $e=w-y$ - input signal to the controller, $u$ - output signal from the controller (control signal). [3, 4]

Using the diagram from Fig. 1. and presenting the object and controller transfer functions in the form with cross power spectral density $\left(S_{x y}\right)$ it is possible to determine the following models: $H_{W}$ (when $z=0$ ) describing the operation of the engine during the ground test and $H_{Z}$ (when $w=0$ ) describing the operation of the engine during the flight. It takes the form: $[4,7]$

$$
\begin{gathered}
H_{W}=\frac{S_{y_{w} u} S_{u e}}{S_{y_{w} u} S_{u e}+S_{u u} S_{e e}} \\
H_{Z}=H_{W} \cdot \frac{1}{G_{R}}=\frac{S_{y_{w} u} S_{e e}}{S_{y_{w} u} S_{u e}+S_{u u} S_{e e}}
\end{gathered}
$$

Thus, by using $H_{W}$ transfer function, the $H_{Z}$ transfer function can be determined. It is therefore possible to determine the characteristics of the engine with input ,z” (on the fly) based only on the signals registered during the engine ground tests when the input signal is ,$w ”$.

\section{Verification of the turbine engine control quality assessment method}

The work of a turbine jet engine during ground tests (with the „w" input) and during the flight (with the input interference signal ,,z") is described by the model shown in Fig. 1. This model for the simulation needs can be presented in the form of two separate models responsible for work from just one of inputs (two SISO models). Fig. 2a shows the model with input ,, $w$ ”, whereas Fig. 2b shows the model with input ,, $z$ ”.

a)

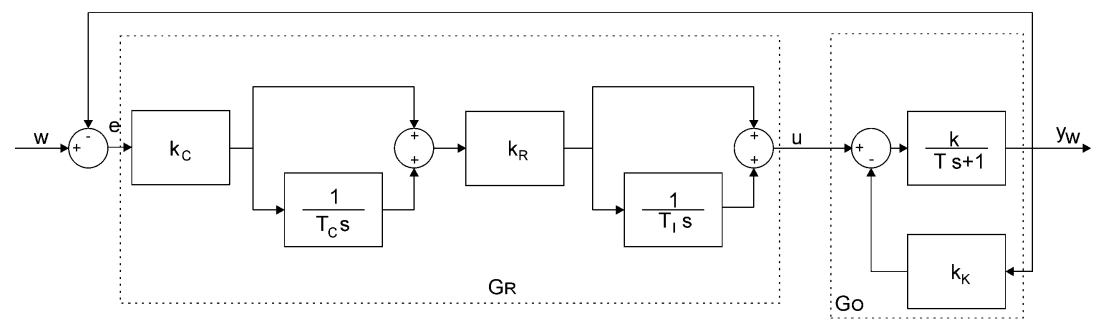

b)

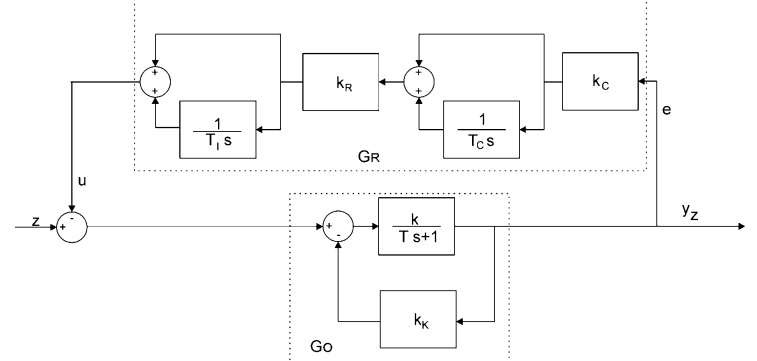

Fig. 2. Simplified model of the engine speed control system, where: a) when input $z=0$ (during ground tests), b) when input $w=0$ (during the flight), $y_{W}$ - system response when the input signal is 
" $w$ " delivered to the controller, $y_{Z}$ - system response when input signal is delivered directly on the object, $T_{i}, T, T_{c}$ - these are the time constants of the controller, the object and the sensor; $k_{C}, k_{R}, k, k_{K}-$ gain for the sensor, controller, object and object compensator. [2, 5, 6, 9, 10]

For selected parameters: $[2,4,9,10,11,12]$ :

$\mathrm{T}=1,7 \quad \mathrm{k}=0,45, \quad \mathrm{k}_{\mathrm{K}}=0,075$

$\mathrm{k}_{\mathrm{R}}=7 \quad \mathrm{~T}_{\mathrm{I}}=2$

$\mathrm{k}_{\mathrm{C}}=0,15 \quad \mathrm{~T}_{\mathrm{C}}=0.35$

Transfer functions of the object and controller from Fig. 2. take the form:

$$
\begin{gathered}
G_{O}(s)=\frac{0,45}{1,7 s+1,034} \\
G_{R}(s)=\frac{0,3675 s^{2}+1,234 s+0,525}{0,35 s^{2}}
\end{gathered}
$$

Thus, transfer functions of the system from , $w$ " and from , $z$ ” take the form:

$$
\begin{gathered}
H_{W}(s)=\frac{0,3307 s^{2}+1,11 s+0,4725}{1,19 s^{3}+1,054 s^{2}+1,11 s+0,4725} \\
H_{W}(s) \cdot \frac{1}{G_{R}(s)}=\frac{0,315 s^{2}}{1,19 s^{3}+1,054 s^{2}+1,11 s+0,4725}=H_{Z}(s)
\end{gathered}
$$

Transfer functions $H_{W}(s)$ and $H_{Z}(s)$ can be written in the frequency domain by substituting $s=j \omega$. The real parts of these Transfer functions for both the , $w$ ” and , $z$, inputs take the form:

$$
\begin{aligned}
\operatorname{Re}_{W}(\omega) & =\frac{\left(27 *\left(-47050 * \omega^{4}+27983 * \omega^{2}+10800\right)\right)}{\left(1849600 * \omega^{6}-1999655 * \omega^{4}+308961 * \omega^{2}+291600\right)} \\
\operatorname{Re}_{Z}(\omega) & =\frac{\left(1800 * \omega^{2} *\left(241 * \omega^{2}-108\right)\right)}{\left(1849600 * \omega^{6}-1999655 * \omega^{4}+308961 * \omega^{2}+291600\right)}
\end{aligned}
$$

In order to prove the correctness of the transformation from (Eq 1. and 2) a simulation of the both models from Fig. 2 (described also by $H_{W}(s)$ (Eq. 5) and $H_{Z}(s)$ Eq. 6) was carried out for step and Dirac delta function as input arguments.
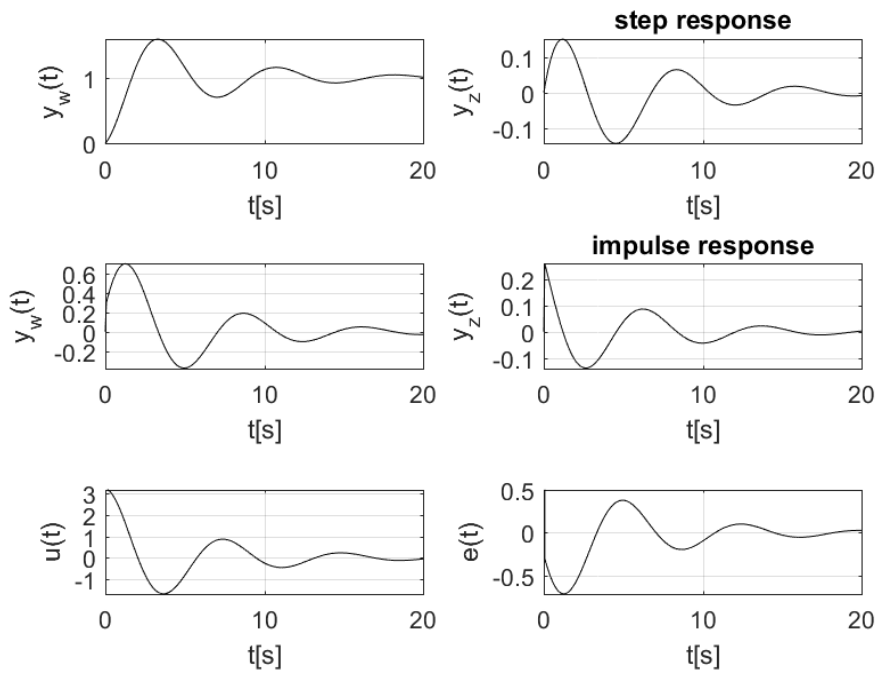

Fig. 3. Step and impulse response of the transfer functions $H_{W}(s)$ and $H_{Z}(s)$. 
Using the signals obtained as results of impulse response from Fig. 3. graphs of real part of transfer functions were made in three variants (Fig. 4.):

a) directly from the For Eq. 7 and Eq. 8

b) $\operatorname{Re}_{2 W}(\omega)=\operatorname{real}\left(\frac{S_{y_{w} w}}{S_{w w}}\right)$ and $\operatorname{Re}_{1 Z}(\omega)=\operatorname{real}\left(\frac{S_{y_{Z} z}}{S_{z z}}\right)$ - using only the input and output signals for describing the $H_{W}$ and $H_{Z}$ models by power spectral density;

c) $\operatorname{Re}_{2 W}(\omega)=\operatorname{real}\left(\frac{S_{y_{w} u} S_{u e}}{S_{y_{w} u} S_{u e}+S_{u u} S_{e e}}\right) \quad$ and $\quad \operatorname{Re}_{2 Z}(\omega)=\operatorname{real}\left(\frac{S_{y_{w} u} S_{e e}}{S_{y_{w} u} S_{u e}+S_{u u} S_{e e}}\right)$

using only the signals from impulse response of $H_{W}(s)$ (Eq. 5): $y_{w}(t), e(t)$ and $u(t)$.
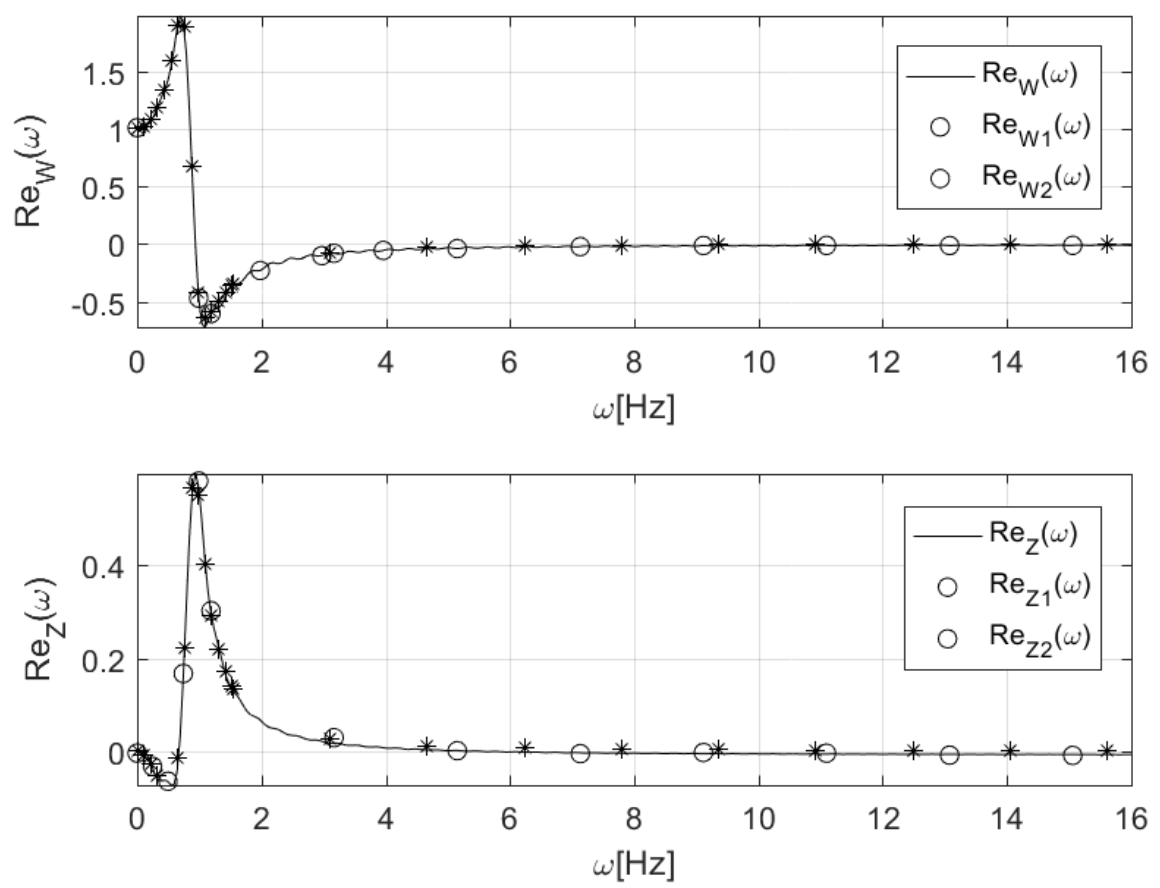

Fig. 4. Comparison of real part of spectral transfer functions obtained from responses on the impulse signal.

In order to transfer from the frequency domain to the time domain, based on the values of the real parts of the spectral transfer functions from impulse response (Fig. 4.) and the transformation from Eq. 9 step responses of the $H_{Z}(s)$ in time domain were obtained [3].

$$
y\left(t_{i}\right)=\sum_{n=1}^{n=\infty} \frac{2}{\pi} \cdot \frac{\sin \left(\omega_{n} \cdot t_{i}\right)}{\omega_{n}} \operatorname{Re}(\omega) \cdot \Delta \omega
$$

The obtained results were compared with $y_{z}(t)$ which is a step response of the $H_{Z}(s)$ (Eq. 6 - Fig. 3) are presented in Fig. 5. 


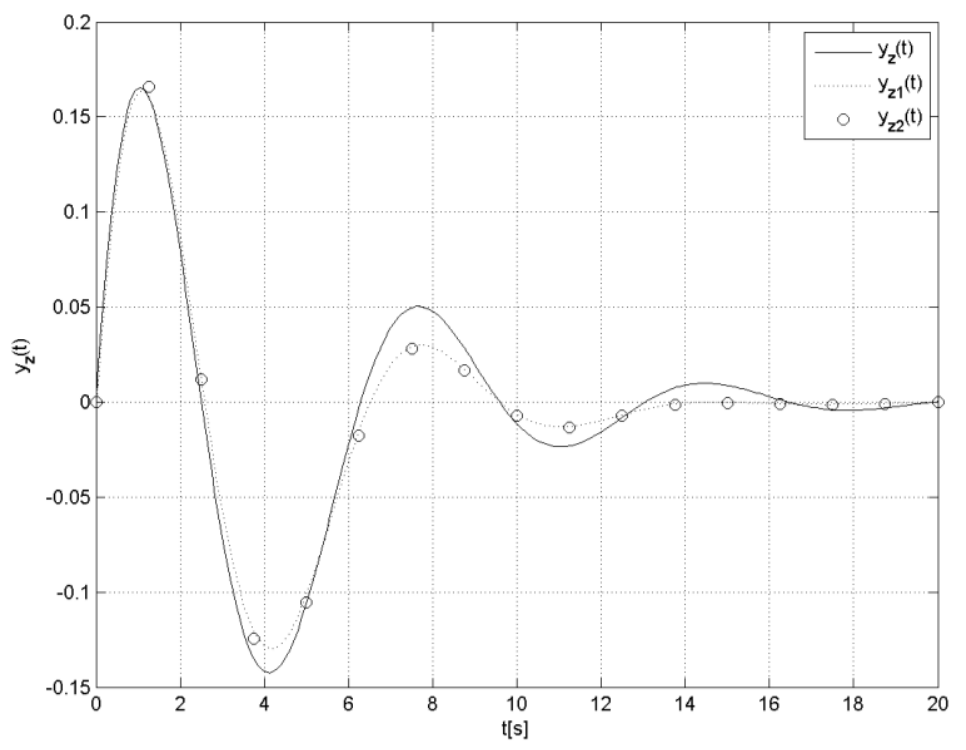

Fig. 5. A comparison of the step responses, where: $y_{z}(t)$ is from Eq. 6 - Fig. 3., $y_{z l}(t)$ from $\operatorname{Re} e_{1}(\omega)$ and Eq. 9, $y_{z 2}(t)$ for $\operatorname{Re}_{z 2}(\omega)$ and Eq. 9.

As shown in Fig. 5, all three step response variants are very similar. This proves the correctness of the proposed method for assessing the state of engine regulation in flight (from , $z$ ") based only on signals registered during the ground test from ,w”.

The accuracy of the obtained results is strongly influenced by two parameters: $\Delta \omega-$ the sampling frequency, and the type of used window function (used for auto and cross correlation necessary to obtain the power spectral density functions $S_{y x}$ ). Their impact is shown below.



Fig. 6. The impact of the sampling frequency $\Delta \omega$ on the $y_{z}(t)$ step response.

Fig. 6 shows the influence of the sampling frequency $\Delta \omega$ on the obtained step response. The waveforms for the four sampling frequencies were calculated. The obtained results 
show a small influence of the sampling rate in the tested range, only $\Delta \omega=0.2 \mathrm{~Hz}$ shows clear deviations from the signal waveform.

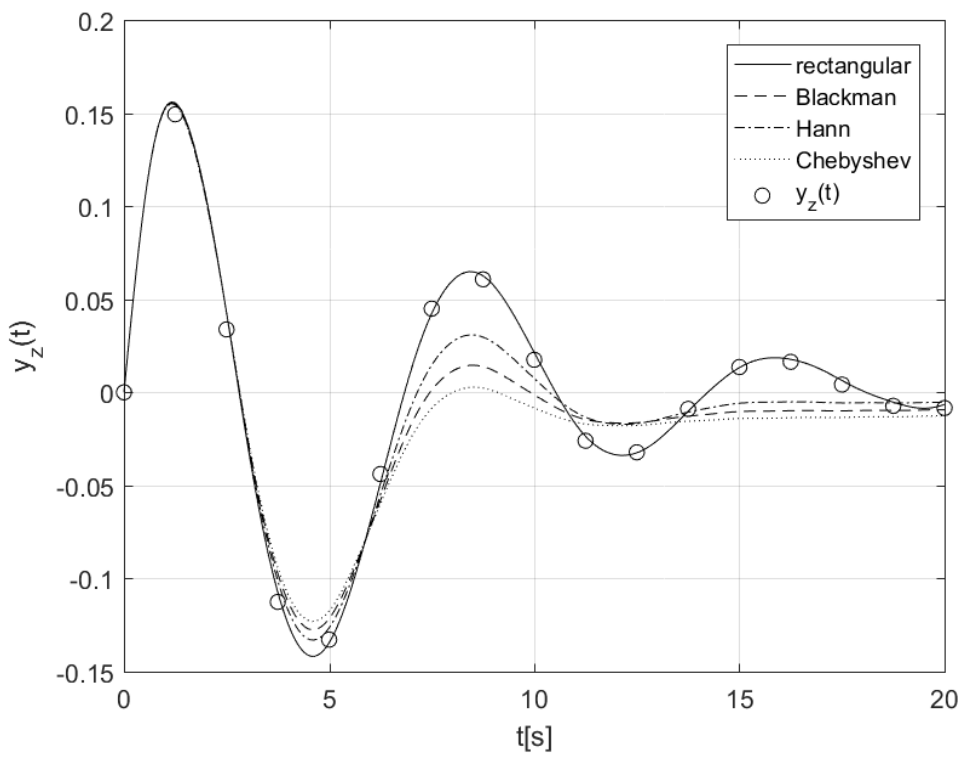

Fig. 7. The impact of the used window function on the $y_{z}(t)$ step response.

Fig. 7 shows the influence of the window functions used. The calculations were carried out for four selected window functions: rectangular, Hanning, Blackman and Chebyshev and compared to the answer obtained directly from $\mathrm{Hz}(\mathrm{s})$ (Eq. 6.). Results show that the best approximation is obtained for a rectangular window. However, for further research it is recommended to use the Hanning window due to the significant noise in signals obtained during ground tests.

\section{Summary}

According to the conducted simulation test, as a result of multiplication of $H_{W}(s)$ (transfer function describing engine during the ground tests) with $1 / G_{R}(s)$ (inverse of the controller transfer function also from ground tests) could be obtained the $H_{Z}(s)$ (which describes the engine during the flight). This fact has been confirmed in the frequency domain using the power spectral density of signals $y_{w}, u, e$ - by comparing the real parts of spectral transfer functions(Fig. 4.).

By using the real parts of transfer functions $\left(\operatorname{Re}_{Z 1}(\omega)\right.$ and $\left.\operatorname{Re}_{Z 2}(\omega)\right)$ obtained from the impulse response and using the transition from the frequency domain to the time domain, the step responses of the model could obtained (Fig. 5.). These responses are very similar to the responses obtained directly from the $H_{Z}(s)$ transmittance (Eq. 6) shown in Fig. 5. Summing up, it is proved that there is a real possibility to assess the engine control quality during the flight based only on signals registered during its ground tests.

The engine characteristics obtained directly from its ground tests will allow the assessment of the impact of engine control changes on its operation. This will allow to propose a more appropriate way to control the engine after the ground test (without the need for flight test), which will reduce the risk associated with the inspection flight carried out after each repair and refurbishment.

This paper was supported by the research project No. S/WM/2/2017 and financed by the Ministry of Science and Higher Education. 


\section{References}

1. W. Balicki, S. Szczeciń ski, Diagnostyka lotniczych silników turbinowych. Zastosowanie symulacyjnych modeli silników do optymalizacji zbioru parametrów diagnostycznych. Biblioteka Naukowa Instytutu Lotnictwa (2001)

2. W. A. Bodner, Automatyka silników lotniczych, Wyd. MON (1958).

3. K. Golak, Parametryczna ocena turbinowego silnika odrzutowego $w$ locie na podstawie jego prób naziemnych (PhD thesis, 2016)

4. K. Golak, P. Lindstedt, R. Grą dzki, Studies of the jet engine control quality based on its response to the disturbance inflicted on the object, designated from its response to the set point inflicted to the controller, In: Safety and Reliability: Methodology and Applications - Proceedings of the European Safety and Reliability Conference, 137- 140 (2014)

5. R. Grądzki, P. Lindstedt, K. Golak, Premises of evaluation of the technical object suitability with including the quality of its maintenance and operation, and their initial conditions. In: Safety and Reliability: Methodology and Applications - Proceedings of the European Safety and Reliability Conference, chapter 44; pp. 319 - 326 (2015)

6. K. Kurman, Teoria regulacji podstawy analiza projektowanie, WNT, (1975)

7. P. Lindstedt, K. Golak: Premises of parametrical assessment of turbojet engine in flight regulation condition during ground test, Acta Mechanica et Automatica, 6, no. 1 (2012)

8. Lindstedt P.: Possibilities of assessment of the potential of Aircraft Engines, Solid State Phenomena, 147-149/2009, Trans Tech Publications, (2009)

9. M. Orkisz, Simulation analysis of the influence of variation in some selected design and control parameters on the acceleration time of a turbojet engine, Engineering Transactions, 39, 3-4 (1991|)

10. W. I. Pawlak, Computer simulation of transient processes in a turbojet engine, with special attention to amplitudes of thermal shocks in some selected fault models of operations, The Archive of Mechanical Engineering, LIV, no 3 (2007)

11. S. Szczeciń ski, Nape d samolotu l-22 IRYDA, WPTiL 3/1995 (1995)

12. A. А. Ше в я ков, Ав тома тика ави аиионн их и

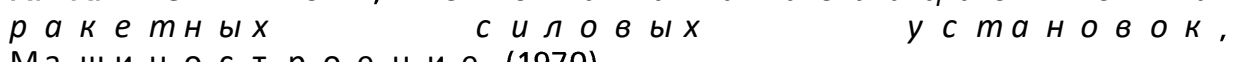
Ма шин о с т р о н и е (1970) 